\title{
A Toll//L-1R/resistance domain-containing thioredoxin regulates phagocytosis in Entamoeba histolytica
}

\author{
Ismael Mancilla-Herrera ${ }^{1,2}$, Alfonso Méndez-Tenorio ${ }^{3}$, Isabel Wong-Baeza ${ }^{1,4}$, Alexis P Jiménez-Uribe , \\ Marcela Alcántara-Hernández ${ }^{1,4}$, Ramon Ocadiz-Ruiz ${ }^{6}$, Mario A Moreno-Eutimio 1,5, Lourdes A Arriaga-Pizano ${ }^{1}$, \\ Constantino López-Macías' ${ }^{1}$, Jorge González-y-Merchand ${ }^{7}$ and Armando Isibasi ${ }^{1 *}$
}

\begin{abstract}
Background: Entamoeba histolytica is a protozoan parasite that infects humans and causes amebiasis affecting developing countries. Phagocytosis of epithelial cells, erythrocytes, leucocytes, and commensal microbiota bacteria is a major pathogenic mechanism used by this parasite. A Toll/IL-1R/Resistance (TIR) domain-containing protein is required in phagocytosis in the social ameba Dictyostelium discoideum, an ameba closely related to Entamoeba histolytica in phylogeny. In insects and vertebrates, TIR domain-containing proteins regulate phagocytic and cell activation. Therefore, we investigated whether E. histolytica expresses TIR domain-containing molecules that may be involved in the phagocytosis of erythrocytes and bacteria.
\end{abstract}

Methods: Using in silico analysis we explored in Entamoeba histolytica databases for TIR domain containing sequences. After silencing TIR domain containing sequences in trophozoites by siRNA we evaluated phagocytosis of erythrocytes and bacteria.

Results: We identified an E. histolytica thioredoxin containing a TIR-like domain. The secondary and tertiary structure of this sequence exhibited structural similarity to TIR domain family. Thioredoxin transcripts silenced in E. histolytica trophozoites decreased erythrocytes and E. coli phagocytosis.

Conclusion: TIR domain-containing thioredoxin of E. histolytica could be an important element in erythrocytes and bacteria phagocytosis.

Keywords: Entamoeba histolytica phagocytosis, Toll/L-1R/resistance domain, Erythrocytes phagocytosis, Bacteria phagocytosis

\section{Background}

Entamoeba histolytica is the etiological agent of amebiasis. It is estimated that this protozoan parasite infects 500 million people worldwide (its prevalence is around $1 \%$ in industrialized countries and reaches $50-80 \%$ in tropical countries, causing 40,000-110,000 deaths per year) [1-3]. Phagocytosis of epithelial cells, erythrocytes, leucocytes and bacteria from the commensal microbiota is a major pathogenic

\footnotetext{
*Correspondence: isibasi@prodigy.net.mx

'Medical Research Unit on Immunochemistry, Specialties Hospital. National Medical Centre "Siglo XXI". Mexican Social Security Institute (IMSS), Mexico City, Mexico

Full list of author information is available at the end of the article
}

mechanism used by E. histolytica. Phagocytosis requires recognition of ligands on target cells and activation of signaling pathways that lead to cytoskeletal reorganization and vesicle trafficking. In E. histolytica, the recognition of target cells is mediated by a galactose $/ \mathrm{N}$-acetylgalactosamine-binding lectin [4-6] and by a phagosome-associated transmembrane kinase (PATMK) that binds phosphatidylserine in host cells [7]. This is a mechanism that involves the recruitment of thiol-specific antioxidants (such as thioredoxins) for phagosome biogenesis and cytoskeletal rearrangement [8-10]. Included in thioredoxin functions are cell protection from oxidants, regulation of transcription factors and protein binding, and catalysis of protein folding [11,12].

\section{Ciomed Central}

(c) 2012 Mancilla-Herrera et al.; licensee BioMed Central Ltd. This is an Open Access article distributed under the terms of the Creative Commons Attribution License (http://creativecommons.org/licenses/by/2.0), which permits unrestricted use, distribution, and reproduction in any medium, provided the original work is properly cited. 
Phagocytosis is essential for the survival of unicellular organisms. In the social ameba Dictyostelium discoideum, a Toll/IL-1R/resistance (TIR) domain-containing protein (TirA) is required for the phagocytosis of bacteria, which is essential for nutrition and for protection against infection [13]. Moreover, phagocytic cells play a central role in the innate immune systems of multicellular organisms, and TIR domain-containing proteins regulate the activation of these cells in insects and vertebrates. The TIR domain encompasses three highly conserved regions; i.e., Box1, Box2, and Box3 [14].

The TIR domain is present in a wide variety of eukaryotic organisms, from free-living amebas (which are closely related to E. histolytica in phylogeny) to insects and vertebrates. It has been suggested that in E. histolytica, the phagocytosis of natural substrates (such as human erythrocytes and E. coli) is mediated by TIR domain-containing proteins that participate in a signaling component that existed before the diversification of eukaryotes [15]. Therefore, in the present study, we investigated whether E. histolytica expresses TIR domain-containing molecules that participate in the regulation of the phagocytosis of human erythrocytes and E. coli. Using an in silico analysis of the E. histolytica proteome, we identified a TIR domain-containing sequence that corresponds to a thioredoxin. Furthermore, the downregulation of this thioredoxin by siRNA led to decrease of phagocytosis of erythrocytes and E. coli by E. histolytica trophozoites. These results suggest that the TIR domain-containing thioredoxin is involved in E. histolytica phagocytosis.

\section{Methods}

In silico analysis of the $E$. histolytica TIR domain-containing sequences

A Hidden Markov Model (HMM) for TIR domain proteins was built with HMMER software v2.3.2 (http://hmmer. janelia.org) and a seed alignment collection of TIR proteins from PFAM database. (Pfam:PF01582, http://www.sanger. ac.uk/Software/Pfam) [16]. Through the HMM, a sequence analysis was implemented to search proteins that contain a probable TIR domain in Protein (NCBI), the Wellcome Trust Sanger Institute (www.sanger.ac.uk), and the Pathema Bioinformatics Resource Center (http://pathema.jcvi.org) databases for Entamoeba genus. Using BLAST (Basic Local Alignment Search Tool, http://blast.ncbi.nlm.nih.gov/Blast. cgi) on E. histolytica proteins of NCBI databases, sequences of primary structure scoring $E$ values $<0.001$ with TIR domain-containing proteins of Entamoeba species were selected as homologous proteins.

The primary and secondary structures of the TIR domain-containing proteins of Entamoeba histolytica identified were compared with the primary structures of the TIR domains of Arabidopsis thaliana (TAO1, GenPept:
ABS82021), Drosophila melanogaster (Toll4, GenPept: AAF52747), and Homo sapiens (IL-1R, TLR2, and MyD88, GenPept: AAB84059, AAH33756 and AAC50954 respectively) by a multiple sequence alignment calculated with T-Coffee (http://tcoffee.crg.cat/). Secondary structures were calculated with the Psipred Protein Structure Prediction Server (http://bioinf.cs.ucl.ac.uk/psipred/). The tertiary structure of the TIR domain of the identified protein was modeled using I-TASSER server (http://zhanglab.ccmb. med.umich.edu/I-TASSER/ $[17,18]$ ) and compared with the tertiary structure of the TIR domain of human interleukin-1 receptor (PDB: 1T3GA). The best structural alignment was calculated by Chimera (http://www.cgl.ucsf. edu/chimera/). The obtained structures were displayed in pdb format using RasMol v. 2.6.

\section{Culture of E. histolytica trophozoites}

Trophozoites of the E. histolytica strain HM-1:IMSS were axenically grown in TYI-S-33 medium, according to Diamond et al. [19]. Trophozoites were grown at $37^{\circ} \mathrm{C}$ for $40-72 \mathrm{~h}$ and harvested by chilling on ice water for $10 \mathrm{~min}$, to detach them from the culture tubes. Trophozoites were washed twice in phosphate-buffered saline solution using low-speed centrifugation $(600 \times \mathrm{g}$ for $5 \mathrm{~min}$ ) and suspended in TYI-S-33 medium to a final concentration of $10^{6}$ cells $/ \mathrm{mL}$.

\section{Reverse transcriptase (RT)-PCR assays}

Total RNA was extracted from E. histolytica trophozoites using the TRIzol reagent (Invitrogen, Carlsbad, CA, USA). RNA was treated with DNase (Qiagen, Germantown, MD, USA) and reverse-transcribed using SuperScript II RNase H-Reverse Transcriptase (Promega, WI, USA). Primers for thioredoxin and PATMK (which was used as an expression control) were designed using Primer3 v.0.4.0 (http:// frodo.wi.mit.edu/primer3 [20]) and actin primers were selected according to background [21]. The final reaction mixture contained $10 \mathrm{nM}$ of each dNTP (Promega), $10 \times \mathrm{Mg}$-free reaction buffer (Promega), $25 \mathrm{mM} \mathrm{MgCl}_{2}$ (Promega), $0.25 \mu \mathrm{l}$ of dimethyl sulfoxide (Sigma, St. Louis, MO, USA), $2.5 \mathrm{U}$ of Taq DNA polymerase (Promega), $0.5 \mu \mathrm{M}$ of each primer (Thioredoxin: sense 5/-GGAGGTAATGGCTGAAATGC-3/, antisense 5/-GGAGGTAAT GGCTGAAATGC-3/; PATMK: sense 5/-AATGGGTG TGCTGTTTGTCA-3/, antisense 5/-CCCTTCAGCACA TCTGTCAC-3/; actin: sense 5-AGCTGTTCTTTCATTATATGC-3, antisense 5-TTCTCTTTCAGCAGTAGTG GT-3, and 100-1,000 ng of cDNA, in a final volume of $25 \mu \mathrm{L}$. The reaction mixture was denatured at $94^{\circ} \mathrm{C}$ for $5 \mathrm{~min}$, followed by 35 cycles of denaturation $\left(94^{\circ} \mathrm{C}\right.$ for $\left.60 \mathrm{~s}\right)$, annealing $\left(59^{\circ} \mathrm{C}\right.$ for $\left.90 \mathrm{~s}\right)$, and extension $\left(72^{\circ} \mathrm{C}\right.$ for $\left.90 \mathrm{~s}\right)$; a final extension of $5 \mathrm{~min}$ at $72^{\circ} \mathrm{C}$ was also performed. PCR products were electrophoresed in $2 \%$ agarose gels at $70 \mathrm{~V}$ for $60 \mathrm{~min}$ and stained with GelRed ${ }^{\mathrm{TM}}$ Nucleic Acid Stain 
(Invitrogen). The density band was documented by a EC3 Bioimaging System (UVP, CA,USA), using ultraviolet illumination. Densitometric analysis was made using VisionWorksLS program v6.4.3 (UVP, CA, USA).

\section{Silencing of gene expression}

Expression of thioredoxin and PATMK were silenced using small interfering double stranded-RNAs (Additional file 1: Table S1), which were designed using the SciTools for RNAi Design from Integrated DNA Technologies (http://www.idtdna.com/Scitools/Applications/RNAi/RNAi. aspx). For each gene, three double-stranded oligonucleotides of 21-23 bp that bound to the initial, mid, and terminal regions of the corresponding transcripts were used. Each oligonucleotide (50, 100 and $250 \mu \mathrm{g}$ ) were added to $10^{6}$ trophozoites in a final volume of $1.0 \mathrm{~mL}$ of TYI-S-33 medium, and the trophozoites were cultured for $15 \mathrm{~h}$ at $37^{\circ} \mathrm{C}$ ("soaking strategy" [22]). The silencing efficiency was evaluated using the RT-PCR approach described above.

\section{Erythrophagocytosis assay}

All experimental procedures were approved by the Local Ethical Committee of Health Research of Specialties Hospital, Mexican Social Security Institute (IMSS), Mexico City, Mexico (Register number. R-2009-3601157). Venous blood (2 mL) from healthy donors was layered over Lymphoprep ${ }^{\mathrm{Tm}}$ (Axis-Shield, Oslo, Norway) and centrifuged at $800 \times g$ for $20 \mathrm{~min}$, to remove mononuclear cells. Erythrocytes were washed and suspended in phosphate-buffered saline solution. Erythrocytes $\left(1 \times 10^{7}\right)$ were incubated with $1 \times 10^{6}$ trophozoites (untreated or in the presence of thioredoxin or PATMK silencing) in $1 \mathrm{~mL}$ of TYI-S-33 medium at $37^{\circ} \mathrm{C}$ for $30 \mathrm{~min}$, with agitation at $150 \mathrm{rpm}$. One milliliter of phosphate-buffered saline solution was added after the incubation, and the culture plate was centrifuged at $600 \times g$ for $5 \mathrm{~min}$. The pellet was lysed in $1 \mathrm{~mL}$ of cold concentrated formic acid (Sigma-Aldrich), and absorbance at $400 \mathrm{~nm}$ was measured using a spectrophotometer (Beckman Coulter, DU ${ }^{\bullet}$ Series 700 UV/Vis Scanning Spectrophotometer). Results were analyzed using Repeated-measures one-way ANOVA and Bonferroni test. Significance was set at $P<0.05$.

\section{Bacteria phagocytosis assay}

The Escherichia coli strain DH- $5 \alpha$ was transformed with a plasmid encoding GFP and an ampicillin resistance gene and grown overnight at $37^{\circ} \mathrm{C}$ in $\mathrm{LB}$ medium with $100 \mathrm{mg} /$ $\mathrm{mL}$ of ampicillin. Bacteria were harvested by centrifugation at $9,000 \times g$ for $10 \mathrm{~min}$, washed three times with phosphate-buffered saline solution, and suspended in phosphate-buffered saline solution to a concentration of $1 \times 10^{8}$ colony forming unit (CFU) per mL. Incubation of $1 \times 10^{8} \mathrm{CFU}$ with $1 \times 10^{6}$ trophozoites (untreated or in the presence of thioredoxin or PATMK silencing) was performed in $1 \mathrm{~mL}$ of TYI-S-33 medium at $37^{\circ} \mathrm{C}$ for 45 min, with agitation at $150 \mathrm{rpm}$. Gentamicin (15 ng) was added after the incubation; $10 \mathrm{~min}$ later, the culture plate was centrifuged at $600 \times g$ for $5 \mathrm{~min}$. The pellet was suspended in $1 \mathrm{~mL}$ of phosphate-buffered saline solution, and the fluorescence of each sample was measured using a flow cytometer (FACS Aria, Becton Dickinson, NJ, USA). At least 10,000 events were acquired per sample. Data were analyzed using BD FACS DiVa software 2.1, and mean fluorescence intensity (MFI) was reported. Results were analyzed using Repeated-measures one-way ANOVA and Bonferroni test. Significance was set at $P<0.05$.

\section{Results}

\section{In silico identification of a TIR domain-containing} thioredoxin in E. histolytica

We generated a HMM from a seed alignment (Pfam: PF01582) of TIR domain and searched proteins containing a TIR domain in Pathema database for Entamoeba genus. Two hypothetical proteins (Pathema:EIN_052840, E value $=0.00039$; and Pathema:EIN_134280, E value $=0.00047)$ and two putative proteins (Pathema:EIN_092020, E value $=0.00047$; and Pathema:EIN_191870, elongation factor 1 -alpha, $\mathrm{E}$ value $=0.0016$ ) were identified. A exploration on Entamoeba histolytica Protein databases for homologues TIR-domain containing proteins of any Entamoeba genus led us to identify a sequence which also contain a thioredoxin domain (GenPept:XP_649779). This whole sequence will be termed "thioredoxin" henceforth.

The putative TIR domain spanned positions 344-442, and its primary structure had low similitude with representative TIR domains from different proteins from different species, including human TLR2, IL1-R, and MyD88, D. melanogaster Toll4, and A. thaliana TAO1 (Figure 1). Even the Box1 and Box2, have structural coincidences, the Box3 exhibited differences in primary (absence of tyrosine residues) and secondary structure (presence of sheets, yellow colored, rather than helixes, red colored).

To demonstrate that the region spanning positions 344 to 442 of this E. histolytica thioredoxin is a member of the TIR family, the 3D protein structure was modeled using a threading strategy on the I-Tasser server (Figure 2, right model). The specific one-on-one 3D structure alignment of the thioredoxin protein sequence with the human Inteleukin-1 Receptor (IL-1R) (Figure 2, left model) and TLR2 (data not shown) TIR domain sequences were determined. These alignments have a root-mean-square distance (RMSD) value of 2.83 and $6.1 \AA$, respectively, which corresponds to the similarity degree of the tridimensional structure of these proteins and suggests that this region is part of the TIR domain family. Accordingly, the 3D model of the TIR protein from E. histolytica was remarkably similar to the TIR domain (Figure 2, superimposition). 

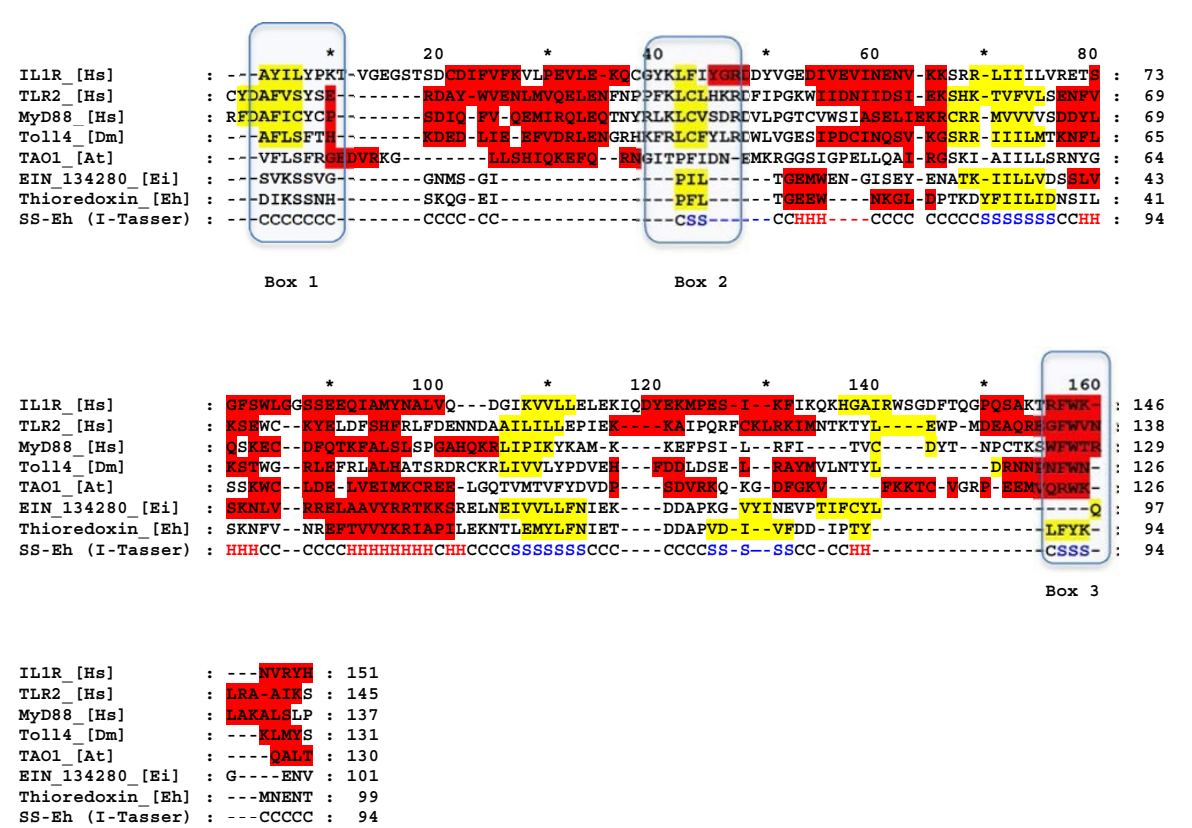

Figure 1 Sequence alignment of TIR domains from several species. Representative sequences are show from: Homo sapiens (IL-1R, TLR2, and MyD88_[Hs]), Drosophila melanogaster (Toll4_[Dm]), Arabidopsis thaliana (TAO1_[At]) as well as the sequences from Entamoeba invadens (EIN_134280_[Ei]) and Entamoeba histolytica (thioredoxin_[Eh]). Colors correspond to secondary structure derived from 3D structures for representative TIR domains, Psipred predictions for EIN_134280_[Ei] and the 3D modeled structure for Thioredoxin_[Eh]: helixes are colored in red and sheets in yellow. The three highly conserved regions previously described in TIR domains [14] are highlighted as boxes 1 to 3. I-Tasser secondary structure assignments are shown at the bottom ( $H=$ helix, $\mathrm{S}=$ sheet).

Silencing of TIR domain-containing thioredoxin decrease the phagocytosis of human erythrocytes and $E$. coli by E. histolytica trophozoites

To show the presence of the region of the mRNA corresponding to TIR domain on thioredoxin transcript, we designed a set of primers which amplified the 344 to 442 region corresponding to thioredoxin protein sequence. We found that E. histolytica trophozoites expressed the
TIR domain-containing thioredoxin mRNA, as assessed using RT-PCR (Figure 3a).

To elucidate the possible participation of TIR domaincontaining thioredoxin in phagocytosis process of erythrocytes and bacteria, we silenced the expression of thioredoxin putative mRNA in E. histolytica trophozoites using small interfering double stranded-RNAs (siRNA) (Additional file 1: Table S1) and evaluated the silencing
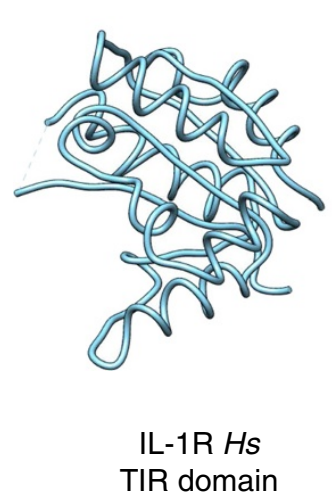

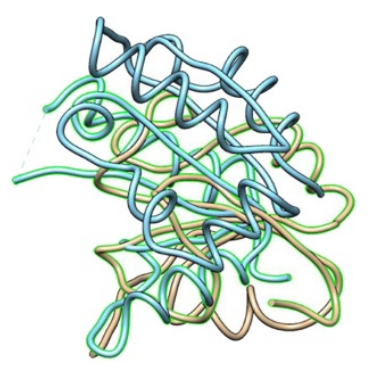

RMSD $=2.83$ Angstroms

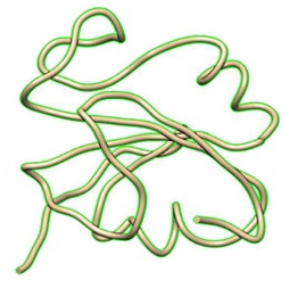

Thioredoxin Eh
TIR domain

Figure 2 Comparison of structures of IL1R from Homo sapiens and Thioredoxin from E. histolytica. TIR domain of human interleukin-1 receptor (PDB: 1T3GA) is show in left model. Tertiary structure of TIR domain-containing thioredoxin was calculated by I-Tasser and show in right model. Structure superimposition is show in the center. (Calculated by Chimera). 


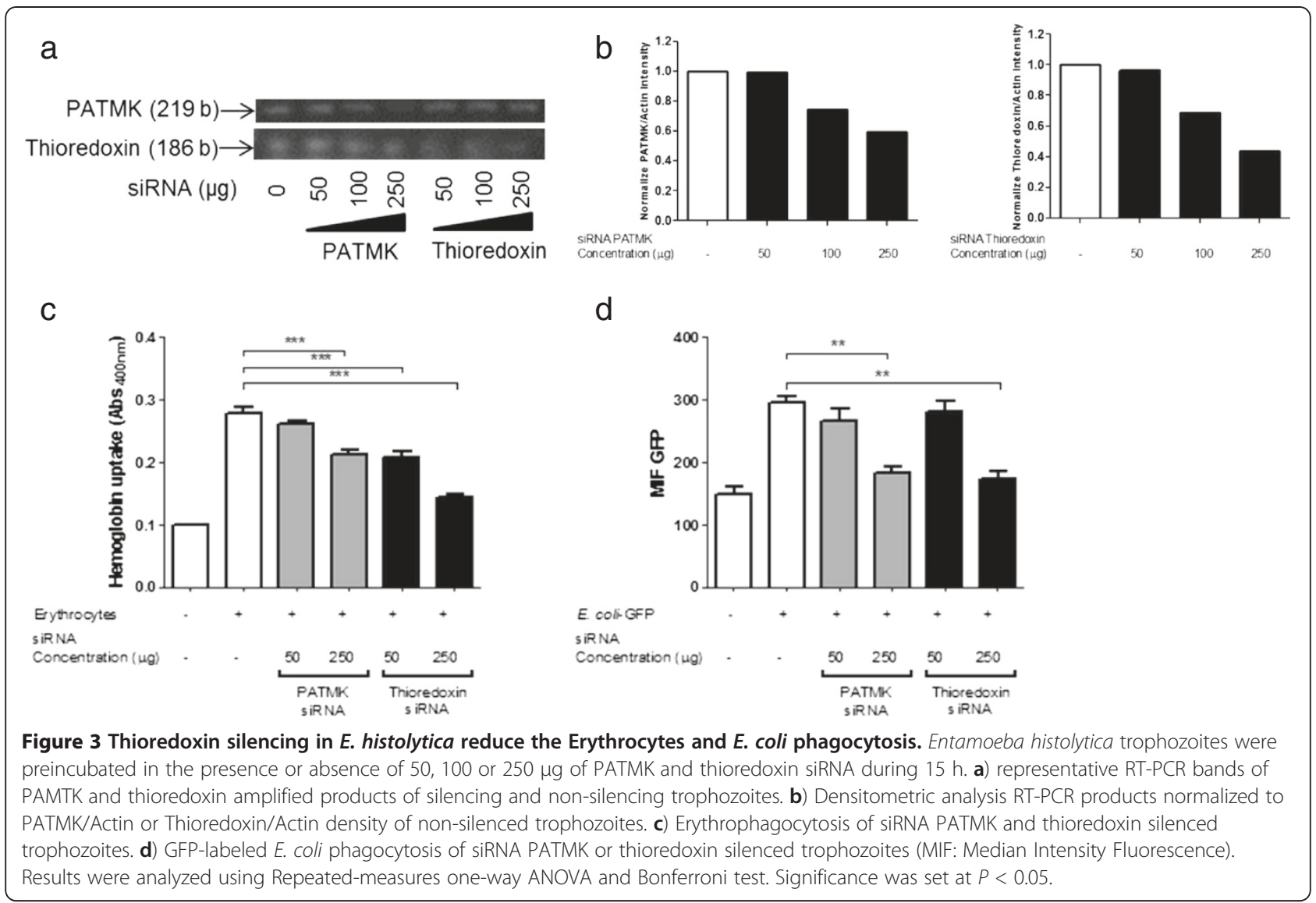

efficiency using RT-PCR. As a positive control of silencing, we also dowregulated the expression of the mRNA of PATMK protein, which has been involve in the initialization of erythrocytes phagocytosis in E. histolytica trophozoites, according to Boettner et al. study. This protein is a good candidate to repressed the phagocytosis process, due the inhibited by three pathways including monoclonal antibodies, mRNA knock-down using shRNA and PATMK gene mutation the reduction on erythrophagocytosis is clear [23].

We observed that 15 hours after the exposition to $250 \mu \mathrm{g}$ of siRNA, the expression of the PATMK mRNA was reduced until $\sim 40 \%$, and the thioredoxin mRNA was reduced by $\sim 60 \%$ (Figure $3 \mathrm{a}$ and $3 \mathrm{~b}$ ). According to literature, the downregulation of PATMK gene expression decreases the capability to phagocyte erythrocytes in trophozoites [23]. In other hand, trophozoites with reduced expression of thioredoxin also exhibited less ability to ingest erythrocytes in a concentration-dependent fashion (Figure 3c). In the same way, downregulation of thioredoxin transcripts, also decreases the capability of trophozoites to engulf $E$. coli-GFP compared with untreated trophozoites (Figure 3d).

Previously, Boettner et al. [23], demonstrated that PATMK silencing decrease the erythrocytes phagocytosis, and in this report we show that PATMK is also required for the bacteria phagocytosis (Figure 3d). All these results suggest that the TIR domain-containing thioredoxin, similar to PATMK, could be associated to a phagocytosis process on E. histolytica trophozoites.

\section{Discussion}

The TIR domain consists of approximately 200 amino acids that form five $\beta$ sheets surrounded by five $\alpha$ helixes [14]. In animals and plants, as well as in free-living amebae, the TIR domain participates in diverse biological activities such as pathogen resistance, immune recognition and feeding [13,24-27]. In this study, we identified a thioredoxin in the E. histolytica proteome which contains a putative TIR domain in a thioredoxin protein. Primary structure of this TIR domain differ from other TIR domains found in plants and animals, but secondary structures show more similar regions, mainly in Box1 and Box 2 that are essential regions to fold the protein, and both are conformed by two helixes [14]. On the other hand, the specific one-on-one 3D structure alignment showed that the thioredoxin has structural analogues of TIR domains in mammalian protein IL-1R and TLR2. This supports the idea that threedimensional structure is much more closely associated 
with function than its lineal sequence, tertiary structure is more evolutionarily conserved than primary structure (http://www.ncbi.nlm.nih.gov/books/NBK22362). Both TIR domains, of mammalian IL-1R and TLR2, mediate homotypic protein-protein interactions in the signal transduction that facilitate the activation and expression of mechanisms which increase several biological process, including phagocytic activity [14,28,29].

The participation of this domain on phagocytosis during infection resistance and feeding observed in the evolutionary related ameba Dictyostelium discoideum [13,15,30], led us to think that the thioredoxin found, may participate in the phagocytosis of natural sources of nutrients through human commensal bacteria (such as Escherichia coli) and erythrocytes to uptake iron [23]. In E. histolytica, phagocytosis process is Gal/GalNAc lectin and PATMK dependent [31].

In this report, we observed reduction in phagocytosis of human erythrocytes and E. coli after incubation with small interfering double stranded-RNAs for thioredoxin, suggesting a role for the TIR domain-containing thioredoxin in trophozoites phagocytosis. These results could support the proteomic approach explored by McCoy et al., and Okada et al. [32,33], which suggest that the phagocytosis process Gal/GalNAc lectin-mediated involves the recruitment of thiol-specific antioxidants (such as thioredoxin) for phagosome biogenesis and cytoskeletal rearrangement [8-10]. If this is right, PATMK and Gal/GalNAc lectin, both of which are involved in the interaction with the membrane of erythrocytes, could be involved in the formation of microdomains necessaries to signaling in phagocytosis, in which molecules like thioredoxin could participate. However this must be investigated further.

The above mentioned, is similar to reported to the majority of these TIR domain-containing proteins that have been described in plants, insects, and vertebrates and participate in phagocytic and cell activation $[13,25]$. However, despite finding similarities among the reduction of phagocytosis when the expression of these transcripts is reduced, according to other reports, we cannot reject the possibility that the thioredoxin identified here participates in the phagocytic process via a mechanism that is not related to its TIR domain, for example the redox state thioredoxin-dependent processes which regulate cellular functions, such as endocytosis and cell adhesion [34-36].

A diverse number of specific functions and cofactor activities have been described for thioredoxins. These functions include growth factor activity, cell protection from toxic compounds (especially oxidants and electrophiles), activation of inflammatory pathways, regulation of transcription factors and protein binding, and catalysis of protein folding; each of these activities has an effect on cellular responses to toxic insults $[11,12]$. However, no other thioredoxin is involved in the regulation of phagocytic processes. E. histolytica expresses other proteins with thioredoxin activity that participate in nicotinamide adenine dinucleotide phosphate (NADPH)-dependent hydrogen peroxide reduction [35]; these detoxifying thioredoxins do not share the TIR domain identified here.

In this report we present evidence that protein sequence corresponding to 344-442 position in E. histolytica thioredoxin (GenPept:XP_649779) has a TIR-domain. Considering that several members of TIR domain family have been involved in signal transduction in many organisms, and silencing its expression decrease erythrocytes and bacteria phagocytosis, the thioredoxin could play a central role in signal transduction during this event, hence influencing the E. histolytica survival mechanisms.

\section{Conclusion}

Uptake of nutrients in Entamoeba histolytica by phagocytosis involves recruitment of proteins such as PATMK, and our results suggest that TIR domain-containing thioredoxin also can support this activity on bacterial and erythrocytes phagocytosis.

\section{Additional file}

Additional file 1: Table S1. Double-stranded oligonucleotides used for the silencing of the expression of thioredoxin and PATMK in E. histolytica trophozoites.

Competing interests

The authors have declared that no competing interests exist.

\section{Authors' contributions}

IMH, AMT, AJU, IWB, and CLM conceived the study, and all authors participated in the study design, coordination and writing the manuscript. All authors read and approved the final manuscript.

\section{Acknowledgements}

This work was supported by Mexican Social Security Institute (IMSS) health research founding (FIS/IMSS/PROT/MD09/732). Mancilla-Herrera received a scholarship by CONACyT (216244). Authors thanks to Ph. D Mario Rodriguez (Departamento de Infectómica y Patogénesis Molecular. Centro de Investigación y de Estudios Avanzados del IPN. A.P. 14-740 México, DF 07360, México) for technical advices, and Hisaki E. for the graphical design.

\section{Author details}

${ }^{1}$ Medical Research Unit on Immunochemistry, Specialties Hospital. National Medical Centre "Siglo XXI". Mexican Social Security Institute (IMSS), Mexico City, Mexico. ${ }^{2}$ Graduate Program on Biomedicine and Biotechnology, ENCB-IPN, Mexico City, Mexico. ${ }^{3}$ Genomic Biotechnology and Bioinformatics Laboratory, Biochemistry Department, National School of Biological Sciences, National Polytechnic Institute (ENCB-IPN), Mexico City, Mexico. ${ }^{4}$ Graduate Program on Immunology, ENCB-IPN, Mexico City, Mexico. ${ }^{5}$ Mexico's Juarez Hospital, SSA, Mexico City, Mexico. ${ }^{6}$ Departamento de Infectómica y Patogénesis Molecular. Departamento de Patología Experimental, Centro de Investigación y de Estudios Avanzados del IPN, México City, México.

${ }^{7}$ Molecular Microbiology Laboratory, Microbiology Department, ENCB-IPN, Mexico City, Mexico.

Received: 22 February 2012 Accepted: 22 September 2012

Published: 8 October 2012 
References

1. Araujo J, Garcia ME, Diaz-Suarez O, Urdaneta H: [Amebiasis: importance of the diagnosis and treatment. Minireview]. Invest Clin 2008, 49:265-271.

2. Blanc DS: Determination of taxonomic status of pathogenic and nonpathogenic Entamoeba histolytica zymodemes using isoenzyme analysis. JProtozoo/ 1992, 39:471-479.

3. Bruckner DA: Amebiasis. ClinMicrobio/Rev 1992, 5:356-369.

4. Petri WA Jr, Schnaar RL: Purification and characterization of galactoseand $\mathrm{N}$-acetylgalactosamine-specific adhesin lectin of Entamoeba histolytica. Methods Enzymol 1995, 253:98-104.

5. Petri WA Jr, Haque R, Mann BJ: The bittersweet interface of parasite and host: lectin-carbohydrate interactions during human invasion by the parasite Entamoeba histolytica. AnnuRev Microbiol 2002, 56:39-64.

6. Haque R, Huston CD, Hughes M, Houpt E, Petri WA Jr: Amebiasis. NEnglJ Med 2003, 348:1565-1573.

7. Boettner DR, Huston CD, Sullivan JA, Petri WA Jr: Entamoeba histolytica and Entamoeba dispar utilize externalized phosphatidylserine for recognition and phagocytosis of erythrocytes. Infect Immun 2005, 73:3422-3430.

8. Tannich E, Horstmann RD, Knobloch J, Arnold HH: Genomic DNA differences between pathogenic and nonpathogenic Entamoeba histolytica. Proc Natl Acad Sci U S A 1989, 86:5118-5122.

9. Poole LB, Chae HZ, Flores BM, Reed SL, Rhee SG, Torian BE: Peroxidase activity of a TSA-like antioxidant protein from a pathogenic amoeba. Free Radic Biol Med 1997, 23:955-959.

10. Bruchhaus I, Richter S, Tannich E: Removal of hydrogen peroxide by the 29 kDa protein of Entamoeba histolytica. Biochem J 1997, 326(Pt 3):785-789.

11. Jin C, Flavell RA: Inflammasome activation. The missing link: how the inflammasome senses oxidative stress. Immunol Cell Biol 2010, 88:510-512.

12. Watson $W H$, Yang $X$, Choi YE, Jones DP, Kehrer JP: Thioredoxin and its role in toxicology. Toxicolsci 2004, 78:3-14.

13. Chen G, Zhuchenko O, Kuspa A: Immune-like Phagocyte activity in the Social Amoeba. Science 2007, 317:678-681.

14. Xu Y, Tao X, Shen B, Horng T, Medzhitov R, Manley JL, Tong L: Structural basis for signal transduction by the Toll/interleukin-1 receptor domains. Nature 2000, 408:111-115.

15. Song J, Xu Q, Olsen R, Loomis WF, Shaulsky G, Kuspa A, Sucgang R: Comparing the Dictyostelium and Entamoeba genomes reveals an ancient split in the Conosa lineage. PLoSComputBiol 2005, 1:e71.

16. Finn RD, Tate J, Mistry J, Coggill PC, Sammut SJ, Hotz HR, Ceric G, Forslund K, Eddy SR, Sonnhammer EL, Bateman A: The Pfam protein families database. Nucleic Acids Res 2008, 36:D281-D288.

17. Roy A, Kucukural A, Zhang Y: I-TASSER: a unified platform for automated protein structure and function prediction. Nat Protoc 2010, 5:725-738.

18. Zhang Y: Template-based modeling and free modeling by I-TASSER in CASP7. Proteins 2007, 69(Suppl 8):108-117.

19. Diamond LS, Harlow DR, Cunnick CC: A new medium for the axenic cultivation of Entamoeba histolytica and other Entamoeba. TransRSocTropMedHyg 1978, 72:431-432.

20. Rozen S, Skaletsky H: Primer3 on the WWW for general users and for biologist programmers. Methods MolBiol 2000, 132:365-386.

21. Banuelos C, Garcia-Rivera G, Lopez-Reyes I, Orozco E: Functional characterization of EhADH112: an Entamoeba histolytica Bro1 domaincontaining protein. Exp Parasitol 2005, 110:292-297.

22. Vayssie L, Vargas M, Weber C, Guillen N: Double-stranded RNA mediates homology-dependent gene silencing of gamma-tubulin in the human parasite Entamoeba histolytica. MolBiochemParasitol 2004, 138:21-28.

23. Boettner DR, Huston CD, Linford AS, Buss SN, Houpt E, Sherman NE, Petri WA Jr: Entamoeba histolytica phagocytosis of human erythrocytes involves PATMK, a member of the transmembrane kinase family. PLoSPathog 2008, 4:e8.

24. Akira S, Takeda K: Toll-like receptor signalling. NatRevImmunol 2004, 4:499-511.

25. Burch-Smith TM, Dinesh-Kumar SP: The functions of plant TIR domains. Sci Signal 2007, 2007:e46.

26. Nurnberger T, Brunner F, Kemmerling B, Piater L: Innate immunity in plants and animals: striking similarities and obvious differences. Immunol Rev 2004, 198:249-266.

27. Sillo A, Bloomfield G, Balest A, Balbo A, Pergolizzi B, Peracino B, Skelton J, Ivens A, Bozzaro S: Genome-wide transcriptional changes induced by phagocytosis or growth on bacteria in Dictyostelium. BMCGenomics 2008, 9:291.

28. Doyle SE, O'Connell RM, Miranda GA, Vaidya SA, Chow EK, Liu PT, Suzuki S, Suzuki N, Modlin RL, Yeh WC, et al: Toll-like receptors induce a phagocytic gene program through p38. J Exp Med 2004, 199:81-90.

29. Hosmane S, Tegenge MA, Rajbhandari L, Uapinyoying P, Kumar NG, Thakor N, Venkatesan A: Toll/interleukin-1 receptor domain-containing adapter inducing interferon-beta mediates microglial phagocytosis of degenerating axons. J Neurosci 2012, 32:7745-7757.

30. Eichinger $L$, Noegel AA: Comparative genomics of Dictyostelium discoideum and Entamoeba histolytica. CurrOpinMicrobiol 2005, 8:606-611.

31. Okada M, Nozaki T: New insights into molecular mechanisms of phagocytosis in Entamoeba histolytica by proteomic analysis. ArchMed Res 2006, 37:244-252.

32. McCoy JJ, Mann BJ: Proteomic analysis of Gal/GalNAc lectin-associated proteins in Entamoeba histolytica. Exp Parasitol 2005, 110:220-225.

33. Okada M, Huston CD, Mann BJ, Petri WA Jr, Kita K, Nozaki T: Proteomic Analysis of Phagocytosis in the Enteric Protozoan Parasite Entamoeba histolytica. Eukaryotic Cell 2005, 4:827-831.

34. Arias DG, Carranza PG, Lujan HD, Iglesias AA, Guerrero SA: Immunolocalization and enzymatic functional characterization of the thioredoxin system in Entamoeba histolytica. Free Radic Biol Med 2008, 45:32-39.

35. Arias DG, Gutierrez CE, Iglesias AA, Guerrero SA: Thioredoxin-linked metabolism in Entamoeba histolytica. Free RadicBiolMed 2007, 42:1496-1505.

36. Vicente JB, Ehrenkaufer GM, Saraiva LM, Teixeira M, Singh U: Entamoeba histolytica modulates a complex repertoire of novel genes in response to oxidative and nitrosative stresses: implications for amebic pathogenesis. Cell Microbiol 2009, 11:51-69.

doi:10.1186/1756-3305-5-224

Cite this article as: Mancilla-Herrera et al: A Toll/IL-1R/resistance domaincontaining thioredoxin regulates phagocytosis in Entamoeba histolytica. Parasites \& Vectors 2012 5:224.

\section{Submit your next manuscript to BioMed Central and take full advantage of:}

- Convenient online submission

- Thorough peer review

- No space constraints or color figure charges

- Immediate publication on acceptance

- Inclusion in PubMed, CAS, Scopus and Google Scholar

- Research which is freely available for redistribution 